\title{
Electrodeposition of a Copper-Tellurium Compound under Diffusion-Limiting Control
}

\author{
Takahiro Ishizaki*1, Daisuke Yata*2 and Akio Fuwa \\ Department of Material Science and Engineering, School of Science and Engineering, Waseda University, Tokyo 169-8555, Japan
}

Copper-tellurium films were electrochemically deposited from a solution containing $\mathrm{CuCl}_{2}, \mathrm{TeO}_{2}$ and $\mathrm{HCl}$. This study revealed the relationship between the copper/tellurium ratio in the solution and the metal ratio in the deposited film. The $\mathrm{Cu} / \mathrm{Te}$ ratio of the deposited film was successfully controlled by conducting electrodeposition under diffusion-limited conditions. The $[\mathrm{Cu}] /[\mathrm{Te}]$ ratio in the solution was linearly related to that of $\mathrm{Cu} / \mathrm{Te}$ in the deposited film, since the partial current density originating from the copper and tellurium ions was directly proportional to the concentration of each. The deposited films crystallized to $\mathrm{Cu}_{2} \mathrm{Te}$ at the $\mathrm{Cu} / \mathrm{Te}$ ratio of 2.5 . The films were deposited at $-0.4 \mathrm{~V}$ vs. $\mathrm{Ag} / \mathrm{AgCl}$ from a solution in which $[\mathrm{Cu}] /[\mathrm{Te}]=2.5,\left[\mathrm{CuCl}_{2}\right]=1.0 \times 10^{-3} \mathrm{M}\left(=\mathrm{kmol} \mathrm{m}^{-3}\right),\left[\mathrm{TeO}_{2}\right]=4.0 \times 10^{-4} \mathrm{M}$, and $\mathrm{pH}=1$.

(Received April 17, 2003; Accepted June 13, 2003)

Keywords: electrochemistry, deposition process, copper telluride

\section{Introduction}

Transition-metal tellurides show a wide range of chemical and physical properties. ${ }^{1)}$ For example, $\mathrm{CuInTe}_{2},{ }^{2)}$ $\mathrm{Pb}_{1-x} \mathrm{Sn}_{x} \mathrm{Te}^{3)} \mathrm{PbTe}^{4)}$ and $\mathrm{Ag}_{2} \mathrm{Te}^{5)}$ have found application in highly efficient solar cells, photo-diode devices, mixed ionic-electronic conductive materials and thermo-element materials, respectively. Copper tellurides ${ }^{6-13)}$ also exhibit thermoelectronic properties and novel topological clusters, similar to C60 and carbon nanotubes. However, copper tellurides have rarely been the subject of study, and have thusfar been prepared only through dry processes such as sputtering and chemical vapor deposition.

Fabricating electronic and optical devices by the electrodeposition of semiconductors is attractive from the viewpoint of cost. The synthesis of tellurides via dry processing requires high growth temperature. Electrodeposition offers the advantage of allowing preparation at lower temperature. However, there have not yet been any reports of electrodeposited binary copper-tellurides. This may be due to tellurium's low solubility in water.

Murase et al. investigated the electrodeposition of CdTe in a $\mathrm{Cd}-\mathrm{Te}-\mathrm{NH}_{4}$ solution. ${ }^{14)}$ The basic solution, $\mathrm{NH}_{4}(\mathrm{aq})$, allowed high solubility of the tellurium and the complex formation of $\mathrm{Cd}-\mathrm{NH}_{4}$. By controlling the composition of this solution, stoichiometrically determined crystallized CdTe films were deposited.

In our present research, we have attempted to control the $\mathrm{Cu} / \mathrm{Te}$ ratio and the degree of crystallinity via electrodeposition under diffusion-limited current conditions. In this paper, we describe the following experimental results for copper-telluride co-deposition under diffusion-limited conditions: (i) the limiting current density for the respective elements obtained in linear sweep voltammetric measurements; (ii) the correlation of the $\mathrm{Cu} / \mathrm{Te}$ ratio in the deposited film with the $[\mathrm{Cu}] /[\mathrm{Te}]$ ratio in the solution; and (iii) the crystalline phase of the deposited films.

\footnotetext{
${ }^{* 1}$ Graduated Student, Waseda University and Japan Science Promotion Research Fellow.

${ }^{* 2}$ Graduate Student, Waseda University.
}

\section{Experimental Procedures}

\subsection{Electrochemical experiments}

A three-electrode cell was employed in this study. A sheet of titanium $(20 \mathrm{~mm} \times 40 \mathrm{~mm})$ (TANAKA KIKINZOKU) was used as a working electrode (cathode). Part of this electrode surface was covered with Teflon adhesive tape so that a known area $(10 \mathrm{~mm} \times 10 \mathrm{~mm})$ was exposed to the electrolyte as the cathode surface. A platinum mesh $(30 \mathrm{~mm} \times 50 \mathrm{~mm})$ was used as a counter electrode (anode) and an $\mathrm{Ag} / \mathrm{AgCl}$ electrode was used for reference. The titanium sheets were polished by emery paper with \#200 to \#2000 grid. Organic contamination on the Ti sheets was sonicated in distilled water. Finally, the sheets were chemically etched for $60 \mathrm{~s}$ in aqueous solutions of $1: 1 \mathrm{v} / \mathrm{v} \mathrm{HNO}_{3}$, $1: 1 \mathrm{v} / \mathrm{v} \mathrm{HCl}$ and $10 \mathrm{wt} \% \mathrm{NaOH}^{15)}$ in that order.

All chemicals were regent grade or the highest available commercial grade and were used as received. Deionized water $\left(7 \times 10^{6} \Omega \mathrm{cm}\right)$ was obtained from an Autostill water system (YAMATO Co., Ltd. WG25). Electrolytes were prepared from $\mathrm{CuCl}_{2}, \mathrm{TeO}_{2}, \mathrm{HCl}$ and distilled-deionized water. The $\mathrm{pH}$ of the electrolytes was adjusted to 1.0. In order to avoid any influence from dissolved oxygen, all electrochemical experiments were conducted after argon reflux for ca. $20 \mathrm{~min}$. The bath temperature was maintained at ca. $30^{\circ} \mathrm{C}$ by a rubber heater. The electrolytic bath was agitated at $100 \mathrm{rpm}$ with a magnetic stirring unit for all electrochemical measurements and syntheses.

Linear sweep voltammetry was conducted using a function generator (HOKUTODENKO HB-104), a potentiostat (HOKUTODENKO HA-501) and an X-Y recorder (YOKOKAWA HOKUSHIN ELECTRIC 3025) at a scan rate of $2 \mathrm{mV} / \mathrm{s}$. The diffusion limited current density $J_{\mathrm{d}}$ values were adopted as the average of the steady current recorded for $30 \mathrm{~min}$. The $J_{\mathrm{d}}$ values for the electrodeposition experiments were determined from $I-t$ transient observation at a fixed polarization potential.

All films were potentiostatically deposited for $30 \mathrm{~min}$. The composition of the films was determined by inductively coupled plasma (ICP) atomic emission spectrophotometry (SEIKO SPS7000A) after the compound was dissolved in a 
$\mathrm{HNO}_{3}$ solution. The crystal structure was examined by X-ray diffraction (XRD) (PHILIPS X'Pert). The XRD spectra were obtained using a powder diffractometer with Cuk $\alpha$ radiation between the range of $20^{\circ}$ and $60^{\circ}$ at a scanning rate of $2 \theta=4^{\circ}$ (degree $\left./ \mathrm{min}\right)$. The XRD peaks were assigned based on JCPDS data.

\subsection{Deposition under diffusion-limited conditions}

Generally, the diffusion limited current density is described as follows: ${ }^{16)}$

$$
J=\frac{n F D C}{\delta}
$$

where $n$ is the electrons per molecule reduced, $F$ is the Faraday constant in $\mathrm{C} \mathrm{mol}^{-1}, D$ is the diffusion constant in $\mathrm{cm}^{2} \mathrm{~s}^{-1}, \delta$ is the diffusion layer thickness in $\mathrm{cm}$, and $C$ is the ion concentration in $\mathrm{mol} \mathrm{cm}{ }^{-3}$. If no other competitive limiting factors are involved in the diffusion region for both ions and the deposition of copper and tellurium is controlled solely by diffusion, the theoretical total cathodic current density in the co-deposition process should be the sum of the individual $J_{\mathrm{d}}$ values for copper and tellurium, as follows:

$$
J_{\mathrm{d}(\text { total })}=J_{\mathrm{d}(\mathrm{Cu})}+J_{\mathrm{d}(\mathrm{Te})}
$$

where $J_{\mathrm{d}(\text { total })}$ is the limiting current density for the compound deposition in $\mathrm{A} \mathrm{m}^{-2}$, and $J_{\mathrm{d}(\mathrm{Cu})}$ and $J_{\mathrm{d}(\mathrm{Te})}$ are the limiting current densities of copper and tellurium in $\mathrm{A} \mathrm{m}^{-2}$, respectively. If we assume $D$ and $\delta$ to be constant within the concentration range used, we can simplify as follows:

$$
J_{\mathrm{d}(\text { total })}=K_{\mathrm{Cu}}[\mathrm{Cu}]+K_{\mathrm{Te}}[\mathrm{Te}]
$$

where $K$ in $\mathrm{A} \mathrm{m}^{-2} \mathrm{M}^{-1}\left(\mathrm{M}=\mathrm{kmol} \mathrm{m}^{-3}\right)$ is the value of the limiting current density at the unit concentration. Equation (3) indicates that the $\mathrm{Cu} / \mathrm{Te}$ ratio of the film can be controlled by the $[\mathrm{Cu}] /[\mathrm{Te}]$ ratio of the solution under diffusion-limited conditions.

\section{Results and Discussion}

\subsection{Cathodic polarization curves}

Figure 1 shows the results of linear sweep voltammetry in solutions containing $5.0 \times 10^{-4}$ to $1.2 \times 10^{-3} \mathrm{M}_{-\mathrm{CuCl}_{2}}$. The current density drastically increased starting from the potential of around $-0.2 \mathrm{~V}$ in the negatively progressing sweep. This current originated from the reduction of copper ions as follows:

$$
\mathrm{Cu}^{2+}+2 \mathrm{e}^{-}=\mathrm{Cu}
$$

At potentials from -0.25 to $-0.55 \mathrm{~V}$, the current density was governed by the ion diffusion rate. The limiting current density at the concentrations of $1.0 \times 10^{-3} \mathrm{M}$ and $5.0 \times 10^{-4} \mathrm{M}$ was about $1.8 \mathrm{~A} \mathrm{~m}^{-2}$ and $0.9 \mathrm{~A} \mathrm{~m}^{-2}$, respectively. The limiting current density doubled when the concentration of copper doubled. Thus, the bath concentration was linearly related to the limiting current density. This relationship was observed in all our experiments. The current density again drastically increased from the potential of $-0.6 \mathrm{~V}$ due to the hydrogen evolution reaction.

Figure 2 shows voltammograms for solutions containing $1.0 \times 10^{-4}$ to $5.0 \times 10^{-4} \mathrm{M}-\mathrm{TeO}_{2}$. Here, the current density

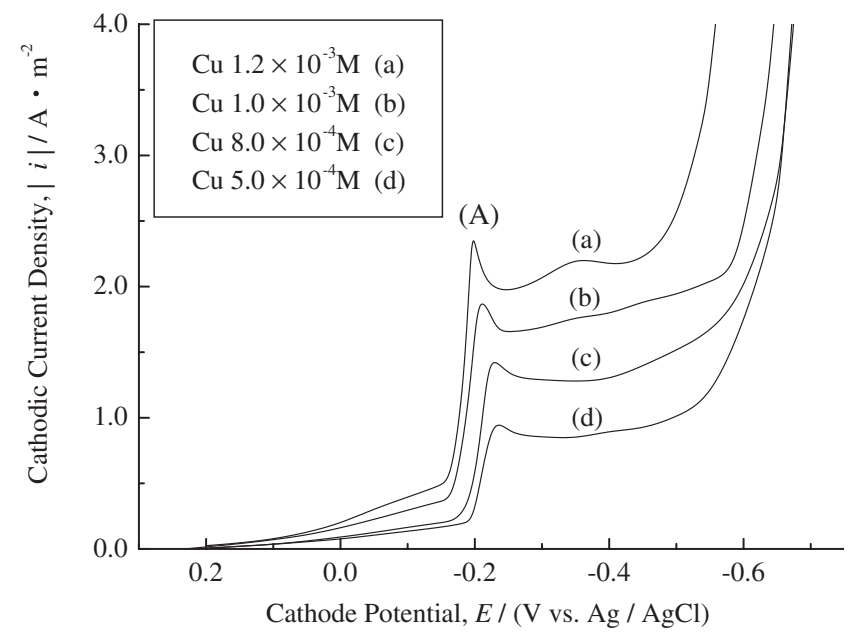

Fig. 1 Linear sweep voltammograms for solutions containing from

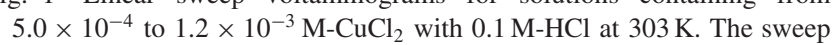
rate was $2 \mathrm{mV} \mathrm{s}^{-1}$.

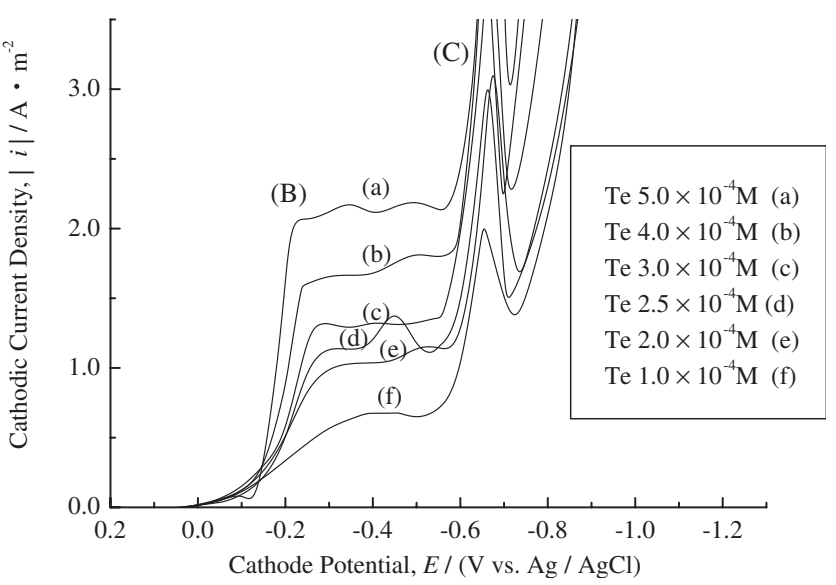

Fig. 2 Linear sweep voltammograms for solutions containing from $1.0 \times 10^{-4}$ to $5.0 \times 10^{-4} \mathrm{M}-\mathrm{TeO}_{2}$ with $0.1 \mathrm{M}-\mathrm{HCl}$ at $303 \mathrm{~K}$. The sweep rate was $2 \mathrm{mV} \mathrm{s}^{-1}$.

drastically increased from around $-0.15 \mathrm{~V}$. This was caused by tellurium deposition as follows:

$$
\mathrm{HTeO}_{2}^{+}+3 \mathrm{H}^{+}+4 \mathrm{e}^{-}=\mathrm{Te}+2 \mathrm{H}_{2} \mathrm{O}
$$

The current density for tellurium deposition reveals a limiting current density at -0.25 to $-0.58 \mathrm{~V}$. The increase of the current density again from $-0.65 \mathrm{~V}$ is thought to result from the following reaction:

$$
\mathrm{Te}+2 \mathrm{H}^{+}+2 \mathrm{e}^{-}=\mathrm{H}_{2} \mathrm{Te}
$$

Another increase of current density from $-0.7 \mathrm{~V}$ is mainly due to the hydrogen evolution reaction. The limiting current density of tellurium also increased with an increase in the ion concentration.

Figure 3 shows $I-t$ transients recorded at $-0.2 \mathrm{~V}$ for a series of solutions of different copper concentrations. The $I-t$ curves display Cottrel behavior for only a short period of time before approaching a constant value. The steady state was typically reached after about $90 \mathrm{~s}$. A similar study for solutions containing tellurium ions revealed the same tendency. 


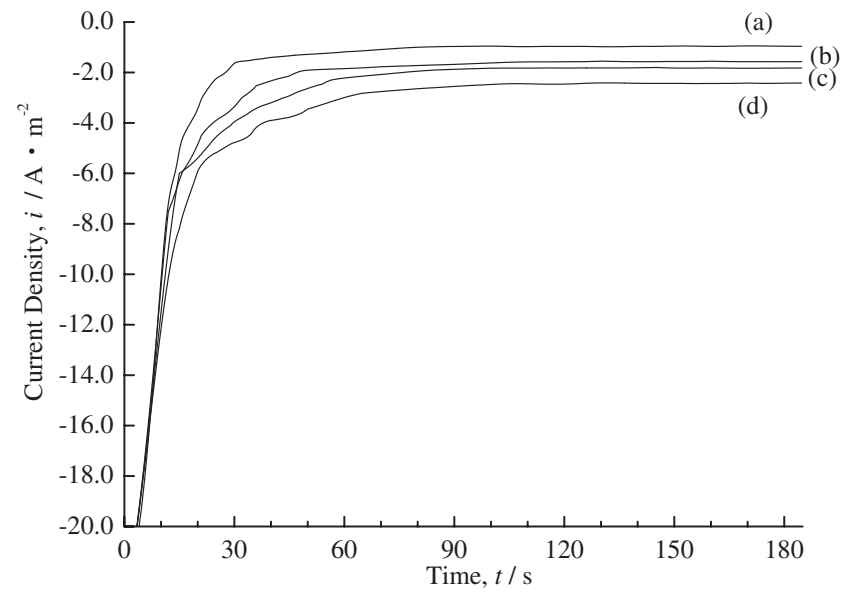

Fig. 3 Current density vs. time profiles for solutions of different $\mathrm{Cu}^{2+}$ concentration: (a) $5.0 \times 10^{-4} \mathrm{M}$; (b) $8.0 \times 10^{-4} \mathrm{M}$; (c) $1.0 \times 10^{-3} \mathrm{M}$; and (d) $1.2 \times 10^{-3} \mathrm{M}$.

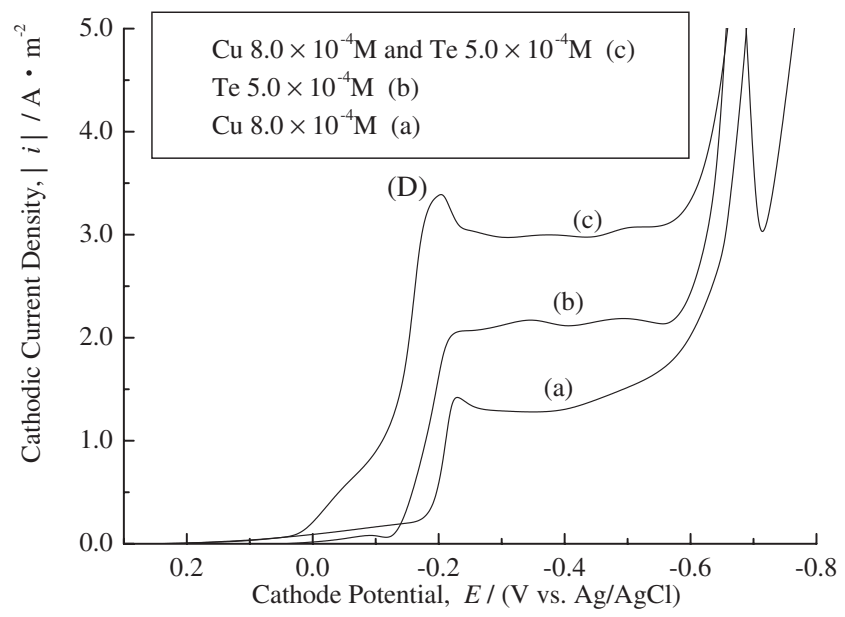

Fig. 4 Linear sweep voltammogram for a mixture solution of

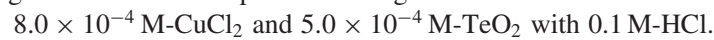

Figure 4 shows the results of linear sweep voltammograms

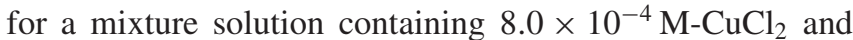

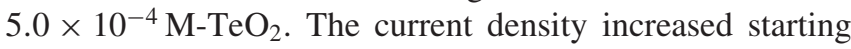
from the potential of around $-0.15 \mathrm{~V}$ due to deposition of the copper-tellurium compound. If the copper-tellurium compound is regarded as $\mathrm{Cu}_{2} \mathrm{Te}$, the electrochemical reaction is considered as follows:

$$
2 \mathrm{Cu}^{2+}+\mathrm{HTeO}_{2}^{+}+3 \mathrm{H}^{+}+8 \mathrm{e}^{-}=\mathrm{Cu}_{2} \mathrm{Te}+2 \mathrm{H}_{2} \mathrm{O}
$$

for which the redox potential at $298 \mathrm{~K}$ is calculated by

$$
\begin{aligned}
E= & 0.507+0.0148 \log \left[\mathrm{Cu}^{2+}\right] \\
& +0.0739 \log \left[\mathrm{HTeO}_{2}^{+}\right]-0.0222 \mathrm{pH}
\end{aligned}
$$

using thermodynamic data. ${ }^{17,18)}$ Under the conditions where $\mathrm{pH}=1,\left[\mathrm{Cu}^{2+}\right]=8.0 \times 10^{-4} \mathrm{M}$ and $\left[\mathrm{HTeO}_{2}^{+}\right]=$ $5.0 \times 10^{-4} \mathrm{M}$, the redox potential is calculated as $0.195 \mathrm{~V}$ vs. $\mathrm{SHE}(=-0.004 \mathrm{~V} \mathrm{Ag} / \mathrm{AgCl})$. This calculated value agrees approximately with that obtained experimentally. The deposition potential for the solution containing the mixture of copper and tellurium shifted in the positive direction compared to that for deposition of either of the respective elements. Since the formation of the copper-tellurium compound produces a negative Gibbs free energy, this may shift the deposition potential of the less noble component to a more positive value. ${ }^{19)}$ As seen in Fig. 4, over the range of -0.2 to $-0.55 \mathrm{~V}$, the sum of the respective limiting current densities of copper and tellurium is almost equal to that of the mixture solution. This tendency was observed in all our results. This indicates that there is hardly any interaction between the diffusion flows of copper and tellurium in the solution. Thus, in this potential range, the composition of the electrodeposited films can be directly controlled according to the solution composition.

\subsection{Diffusion Control}

Figure 5 shows the limiting current density as a function of copper ion concentration. Lines (1) to (3) represent different concentrations of tellurium: (1) no tellurium, (2) $2.0 \times 10^{-4} \mathrm{M}$, and (3) $4.0 \times 10^{-4} \mathrm{M}$. The experimental plots were extrapolated as the dashed lines seen in the figure. The limiting current density increased linearly with the increase in copper ion concentration. Thus, the limiting current density for copper diffusion was shown to be affected little by simultaneous tellurium deposition.

Similarly, Fig. 6 shows the limiting current density as a function of tellurium concentration in solutions containing different amounts of copper. Lines (1) to (3) correspond to no copper, $5.0 \times 10^{-4}$ and $1.0 \times 10^{-3} \mathrm{M}$, respectively. Thus, the limiting current density for tellurium diffusion was also shown to be little affected by simultaneous copper deposition. The extrapolated values in the experimental plots are very close to the diffusion limited current density values observed in Fig. 1. This indicates that hydrogen reduction can be ignored within the appropriate potential range. These results demonstrate that copper and tellurium can be electrochemically co-deposited.

The composition molar ratio $R_{\mathrm{f}}$ of the deposited film can be described by the respective limiting current densities:

$$
R_{\mathrm{f}}=[C u / T e]_{\mathrm{film}}=\frac{J_{\mathrm{d}(\mathrm{Cu})} / n_{\mathrm{Cu}}}{J_{\mathrm{d}(\mathrm{Te})} / n_{\mathrm{Te}}}
$$

where $n$ is the number of electrons per molecule reduced.

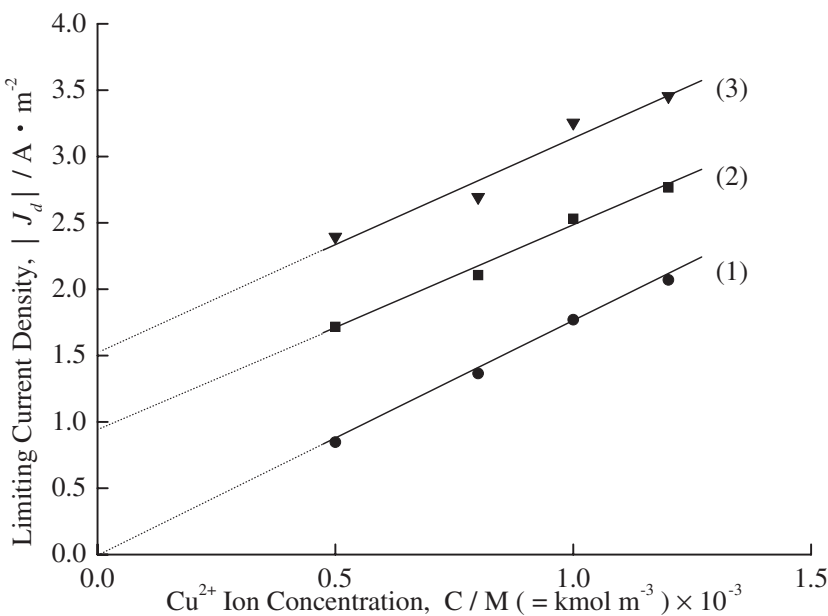

Fig. 5 Total diffusion limited current density vs. $\mathrm{Cu}^{2+}$ ion concentration for three solutions containing different amounts of $\mathrm{HTeO}_{2}^{+}$ions: (1) no tellurium added; (2) $2.0 \times 10^{-4} \mathrm{M}-\mathrm{Te}$; and (3) $4.0 \times 10^{-4} \mathrm{M}-\mathrm{Te}$. The slopes of the plots are, respectively, 164,145 and $149 \mathrm{~A} \mathrm{~m}^{-2} \mathrm{M}^{-1}$. 


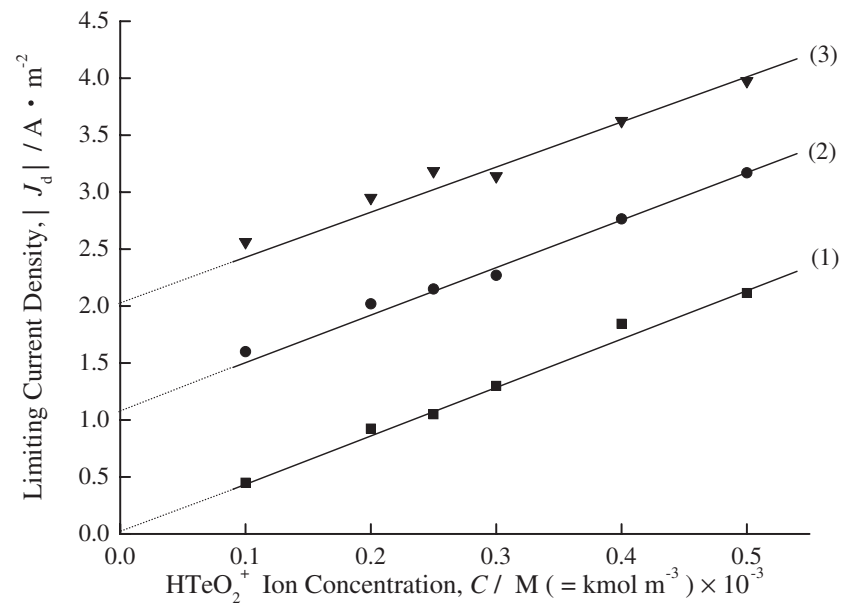

Fig. 6 Total diffusion limited current density vs. $\mathrm{HTeO}_{2}^{+}$ion concentration for three solutions containing different amounts of $\mathrm{Cu}^{2+}$ ions: (1) no copper added; (2) $5.0 \times 10^{-4} \mathrm{M}-\mathrm{Cu}$; and (3) $1.0 \times 10^{-3} \mathrm{M}-\mathrm{Cu}$. The slopes of the plots are, respectively, 425,417 and $396 \mathrm{~A} \mathrm{~m}^{-2} \mathrm{M}^{-1}$.

From eq. (3), we can write as follows:

$$
R_{\mathrm{f}}=\frac{K_{\mathrm{Cu}}[\mathrm{Cu}] n_{\mathrm{Te}}}{K_{\mathrm{Te}}[T e] n_{\mathrm{Cu}}}
$$

Since the values of $K_{\mathrm{Cu}}$ and $K_{\mathrm{Te}}$ in $\mathrm{A} \mathrm{m}^{-2} \mathrm{M}^{-1}$ are given by the slopes of the plots in Figs. 5 and 6, respectively, we can describe the ratio, $R_{\mathrm{f}}$, as follows:

$$
R_{\mathrm{f}}=\frac{152( \pm 12)}{415( \pm 12)} \frac{4}{2} \frac{[\mathrm{Cu}]}{[\mathrm{Te}]}=0.72( \pm 0.02) \frac{[\mathrm{Cu}]}{[\mathrm{Te}]}
$$

\subsection{Film deposition under controlled diffusion}

The $[\mathrm{Cu}] /[\mathrm{Te}]$ ratio in the solution was changed from 1 to 5 while keeping the tellurium ion concentration constant at $2.0 \times 10^{-4} \mathrm{M}$. All the films were potentiostatically deposited at $-0.4 \mathrm{~V}$, where, as demonstrated earlier, the current density would be governed solely by the diffusion rate. The total charge for each film was about $5000 \mathrm{C} \mathrm{m}^{-2}$. The films obtained were about $1 \mu \mathrm{m}$ thick, with the deposition rate corresponding to about $2 \mu \mathrm{m} \mathrm{h}^{-1}$ at $3 \mathrm{~A} \mathrm{~m}^{-2}$. Figure 7 shows

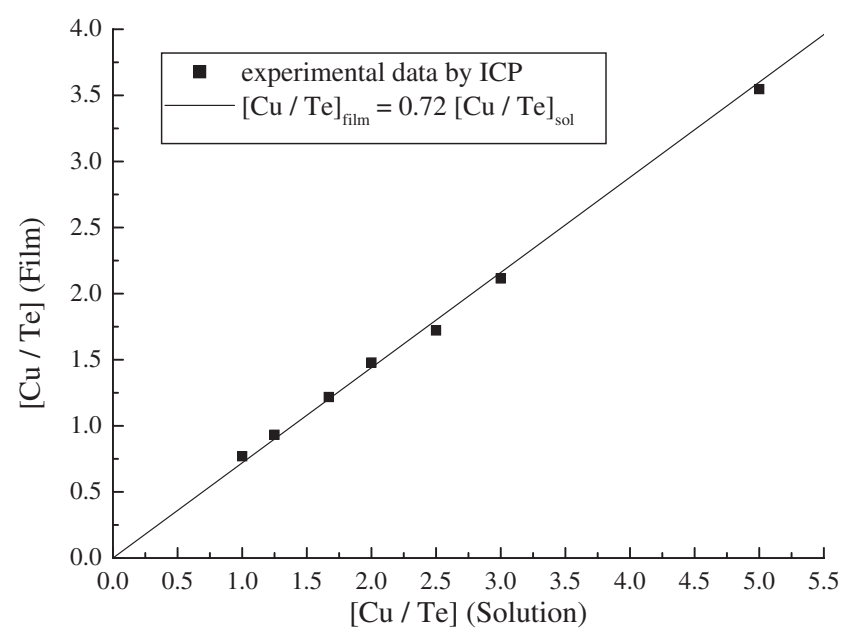

Fig. 7 Copper to tellurium ratio, as measured by ICP, for a set of films deposited in solutions of different $[\mathrm{Cu}] /[\mathrm{Te}]$ compositions. The solid line was calculated based on eq. (6).

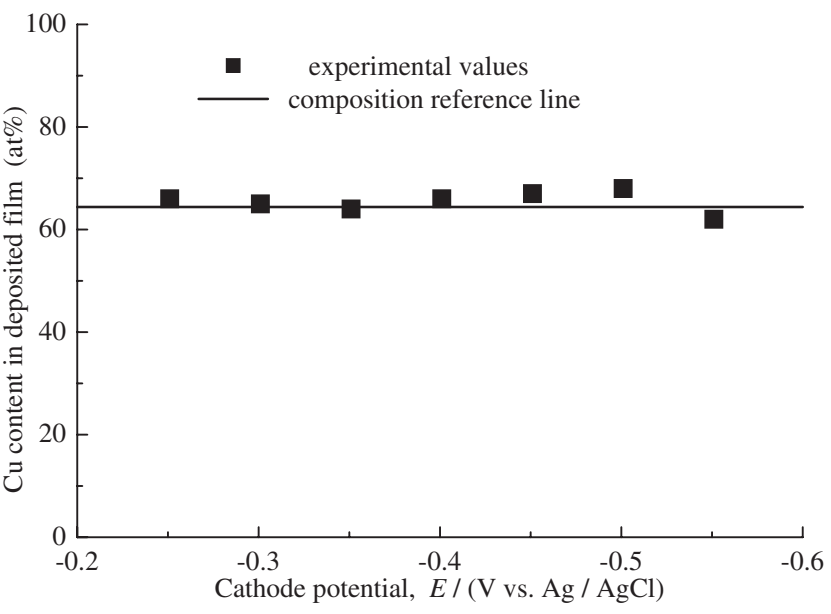

Fig. 8 The relationship between composition and deposition potential under potentiostatic electrodeposition at $303 \mathrm{~K}$ from a bath containing

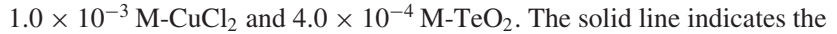
composition reference line.

the composition of the films as measured by ICP analysis correlated with calculations obtained with eq. (6) (indicated by the solid line). The $\mathrm{Cu} / \mathrm{Te}$ ratio of the films was linearly related to the $[\mathrm{Cu}] /[\mathrm{Te}]$ ratio of the solution. Moreover, eq. (6) accurately represented the relationship demonstrated by the experimental results. Thus, eq. (6) effectively provides us with the solution composition necessary to prepare a given film.

Films were then potentiostatically electrodeposited at -0.25 to $-0.55 \mathrm{~V}$ at intervals of $0.05 \mathrm{~V}$ from a bath containing $1.0 \times 10^{-3} \mathrm{M}_{-} \mathrm{CuCl}_{2}$ and $4.0 \times 10^{-4} \mathrm{M}^{-} \mathrm{TeO}_{2}$. These potentials are within the range where control would be solely by the diffusion rate. As shown in Fig. 8, the $\mathrm{Cu} / \mathrm{Te}$ ratio in the deposited films was constant at 1.78 . Thus, the $\mathrm{Cu} / \mathrm{Te}$ ratio in the films was independent of the deposition potential under the diffusion-limited condition.

Figure 9 shows XRD patterns for samples which were deposited at different potentials from (a) $-0.35 \mathrm{~V}$ and (b) -0.25 to $-0.55 \mathrm{~V}$ from a bath containing $1.0 \times 10^{-3} \mathrm{M}$ $\mathrm{CuCl}_{2}$ and $4.0 \times 10^{-4} \mathrm{M}-\mathrm{TeO}_{2}$. The films deposited over this potential range showed diffraction corresponding to the (100) plane of crystalline $\mathrm{Cu}_{2} \mathrm{Te}^{20)}$ In particular, the sample with the $\mathrm{Cu} / \mathrm{Te}$ ratio closest to 1.78 , i.e., the film deposited at $-0.35 \mathrm{~V}$, which had a $\mathrm{Cu} / \mathrm{Te}$ ratio of $1.7-1.8$, showed the sharpest diffraction peak. In contrast, the film deposited at $-0.55 \mathrm{~V}$ exhibited a rather broad diffraction peak. The potential applied may promote the inverse segregation of tellurium.

\section{Conclusions}

We successfully controlled the $\mathrm{Cu} / \mathrm{Te}$ ratio to prepare crystalline $\mathrm{Cu}_{2} \mathrm{Te}$ film via electrodepostion. The coppertellurium films were co-deposited under diffusion-limited, potentiostatic conditions. The diffusion-limiting condition was elucidated by examining, through linear sweep voltammetry, a series of copper-tellurium compound deposits obtained from solutions of different compositions. The limiting current density for the diffusion of copper was not affected by the simultaneous deposition of tellurium ions. 


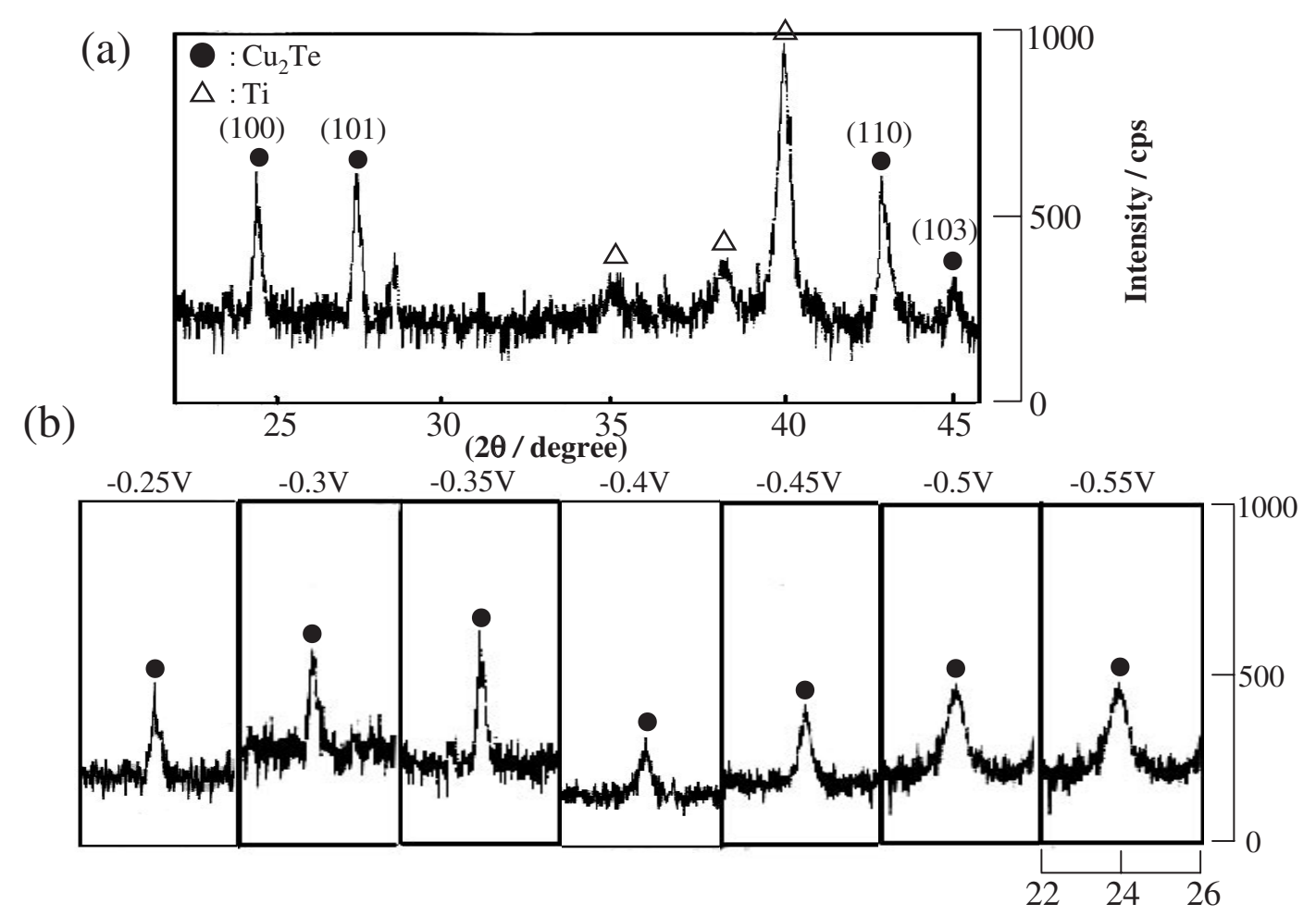

Fig. 9 X-Ray diffraction patterns of films electrodeposited at $303 \mathrm{~K}$ from hydrochloric acid electrolytes $([\mathrm{HCl}]=0.1 \mathrm{M}, \mathrm{pH}=1.0)$ containing $1.0 \times 10^{-3} \mathrm{M}_{-}-\mathrm{CuCl}_{2}$ and $4.0 \times 10^{-4} \mathrm{M}_{-}-\mathrm{TeO}_{2}$. The film in (a) was deposited at $-0.35 \mathrm{~V}$, while the films in (b) were obtained in the potential region between -0.25 and $-0.55 \mathrm{~V}$.

This indicated that copper and tellurium were co-deposited onto the electrode surface. The $\mathrm{Cu} / \mathrm{Te}$ ratio in the films, as measured by inductively coupled plasma (ICP), showed a linear correlation with the $[\mathrm{Cu}] /[\mathrm{Te}]$ ratio in the solution. The $\mathrm{Cu} / \mathrm{Te}$ ratio in the film was barely affected by difference in the deposition potential. Crystalline $\mathrm{Cu}_{2} \mathrm{Te}$ films were obtained with potentials of -0.25 to $-0.55 \mathrm{~V}$ vs. $\mathrm{Ag} / \mathrm{AgCl}$. The film closest to the stoichiometry showed a sharp diffraction peak. The process control demonstrated in this study will allow the preparation of various semiconductors considering the material design.

\section{REFERENCES}

1) P. Bottcher: Agnew. Chem. Int. Ed. Engl. 27 (1988) 759-772.

2) C. D. Lokhande and S. H. Pawar: J. Phys. D: Appl. Phys. 20 (1987) 1213-1214.

3) I. S. Chuprakov and KH. Dahmen: Chem. Mater. 10 (1998) 3467-3470.

4) H. Saloniemi, T. Kanniainen, M. Ritala and M. Leskela: Thin Solid Films 326 (1998) 78-82.

5) R. Chen, D. Xu, G. Guo and L. Gui: J. Mater. Chem. 12 (2002) 24352438.

6) J. W. Gardner: Engl. Electr. J. 18 (1963) 16-21.
7) W. Lehmunn: J. Electrochem. Soc. 104 (1957) 45-50.

8) D. A. Cusano: Solid State Electron. 6 (1963) 217-232.

9) M. Aven and D. A. Cusano: J. Appl. Phys. 35 (1964) 606-611.

10) P. J. Mosticat: Phys. Status Solidi. 11 (1972) 531-538.

11) G. P. Sorokin, G. Z. Idrichan, L. V. Derkach, E. V. Kovton and Z. M. Sorokina: Izv. Akad. Nauk S. S. S. R. Neorg. Mater. 10 (1974) 969974.

12) K. Srudhar and K. Chattopadhyay: J. Alloys Compd. 264 (1998) 293298.

13) B. Li, Y. Xie, J. Huang, Y. Liu and Y. Qian: Chem. Mater. 12 (2000) 2614-2616.

14) K. Murase, H, Uchida, T. Hirato and Y. Awakura: J. Electrochem. Soc. 146 (1999) 531-536.

15) J. Herrero and J. Ortega: Sol. Energy Mater. 17 (1998) 357-368.

16) Allen J. Bard and Larry R. Faulkner: Electrochemical Methods, (John Wiley and Sons, Inc, United States of America, 1980) p. 32.

17) I. Barin: Thermochemical Data of Pure Substances Part II, (VCH, 1989).

18) M. Pourbaix: Atlas of Electrochemical Equilibria in Aqueous Solution, (Pregamon Press, Oxford, 1966) p. 385.

19) R. K. Pandey and S. N. Chandra: Handbook of Semiconductor Electrodeposition, (Marcel Dekker, Inc, New York, 1996) p. 44.

20) JCPDS Data Base, Card No. 39-1061 (unindexed peaks), JCPDS, Swarthmore, PA. 